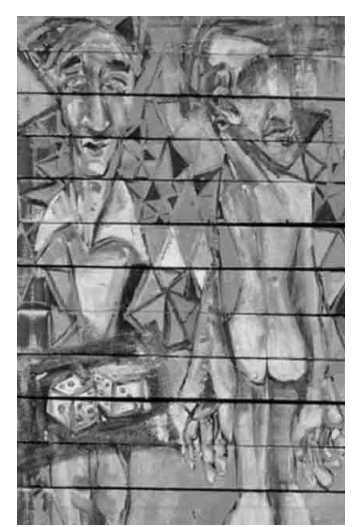

\title{
El pozo: usos, seguridad y tradición en la subcuenca del río San Javier
}

Wells: usage, safety and tradition in San Javier subbasin

Manuel Chávez Valdez*

Gladys Rivera Herrejón**

Tonatiuh Romero Contreras****

Ivonne Vizcarra Bordi**

Fecha de recepción: febrero de 2012

Fecha de aceptación: mayo de 2012

* Doctorante en Ciencias Agropecuarias y Recursos Naturales

Universidad Autónoma del Estado de México

**Instituto de Ciencias Agropecuarias y Rurales

Dirección para correspondencia: griverah@uaemex.mx

***Universidad Autónoma del Estado de México 

El objetivo de la investigación fue conocer la contribución de los pozos tradicionales en el suministro de agua a la población rural vis a vis las redes de agua potable en cinco comunidades rurales de bajos ingresos en el poniente del Estado de México. La información se obtuvo mediante trabajo de campo, entrevistas a informantes clave y usuarios. Se encontró que, en la mayoría de las localidades, los pozos tradicionales se han convertido en la principal fuente de abastecimiento para uso doméstico y que ayudan a resolver la grave crisis del agua. Si bien los pozos son un patrimonio familiar, cumplen una función social más ya que por lo regular son compartidos de manera gratuita con vecinos. La tecnología y el costo en de construcción y operación están al alcance de las familias rurales. Los pozos contribuyen a brindar seguridad en el suministro de agua durante el año.

Palabras clave: agua, pozos tradicionales, zonas rurales, uso y manejo.
The objective of the research was to study the role of traditional wells in water supply for the rural population, vis a vis drinking water networks in five rural low-income villages in the west of the State of Mexico. The information was obtained through field trips and interviews with key informants and users. It was found that in most of the villages, wells are the main source of water for domestic use and they greatly help to solve the serious crisis of lack of water arising from the dysfunctional drinking water networks. While wells are a family heritage, they play a wider social role because they are shared with neighbors free of charge. In addition, the costs of the construction of wells, their operation, and the required technology are within reach of the poor rural families. In conclusion, wells are decisively contributing in the area to provide security in the water supply during the year.

Key words: water, traditional wells, rural areas, use and management. 



\section{Introducción}

l objetivo de la investigación fue conocer las posibilidades de acceso de las familias y la función social de los pozos tradicionales en el suministro de agua a la población rural vis a vis las redes de agua potable en cinco comunidades rurales del poniente del Estado de México, así como identificar y caracterizar los métodos constructivos y de operación.

El aprovechamiento del agua subterránea a través de pozos tradicionales, es decir, aquellos que se excavan a mano, con herramientas simples y que, por lo regular, escasa profundidad porque aprovechan aguas superficiales (Chávez, 1989), se conoce desde tiempos inmemoriales (De Reina y De Valera, 1990).

En la América precolombina, los mayas estaban en posibilidad de extraer agua para consumo humano de los cenotes, los cuales son oquedades en el suelo, ocasionadas por derrumbes naturales que dejan a la vista corrientes subterráneas. En la zona, también se han encontrado los chultunes que son depresiones en forma de botella, excavadas en la roca caliza, destinadas a captar agua de lluvia. Asimismo los mayas excavaban pozos en la roca calcárea para alcanzar los depósitos subterráneos (Rojas et ál., 2009:40-47). En otras ciudades antiguas se han encontrado restos de construcciones que podrían ser pozos. Por ejemplo, en el edificio de Quetzalpapalótl, en Teotihuacan, en la parte sur se encuentra un pozo o noria de dieciocho metros de profundidad, aproximadamente, el cual se piensa fue utilizado para extraer agua. Los casos más notorios de uso de pozos en la época precolombina se encuentran en Tehuacán, Puebla y en Etla, Oaxaca. Actualmente, son denominados pocerías y todavía se perforan al interior de las parcelas para extraer agua para riego (Henao, 2000; González y Terrazas, 2006).

Después de la conquista española, en América, se difundió la construcción y el uso de los pozos someros con las técnicas del Viejo Mundo, sobre todo en 
Figura 1. Pozo en casa de la familia Ramírez, ejido de Jesús María, municipio de Villa Victoria, Estado de México

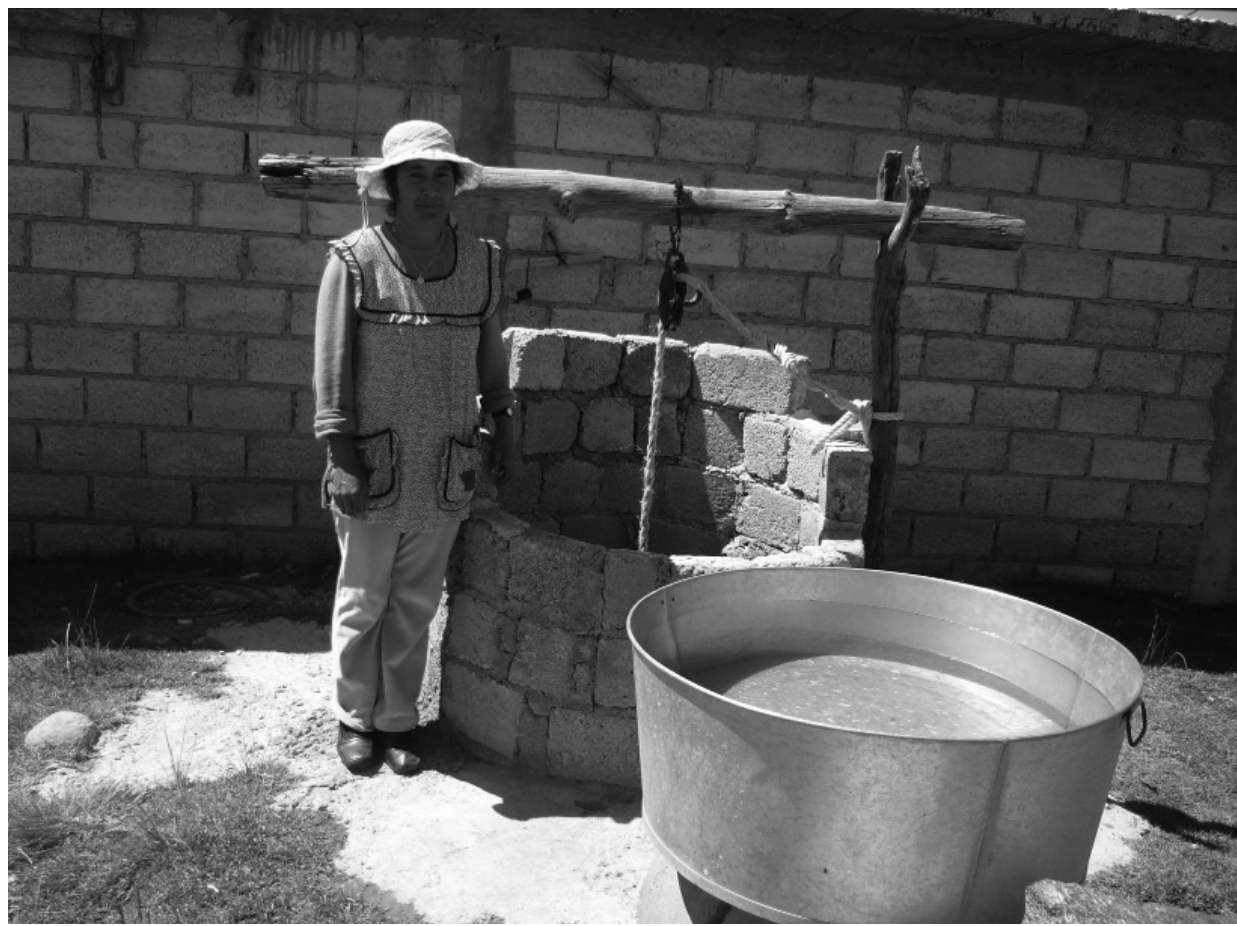

Fuente: foto Manuel Chávez, 2011.

los conventos y en las haciendas (Del Valle, 1991). Tal es el caso del convento Agustino de Actopan, Hidalgo, en cuyo interior se encontraron cuatro pozos (Franco, 2004). Actualmente, el agua subterránea se destina al abastecimiento de agua potable de poblaciones, al riego agrícola y uso pecuario, así como al uso industrial. Sus formas de aprovechamiento son mediante pozos artesianos, manantiales, galerías filtrantes, pozos someros o norias y pozos profundos (Del Valle, 1991).

Los pozos tradicionales, de tecnología antigua, se cavan a mano con picos y palas hasta alcanzar la "tabla de agua", es decir el nivel superior de aguas subterráneas someras o aguas freáticas de un acuífero (véase figura 1). Los pozos cavados a mano regularmente alcanzan una profundidad de seis a doce metros, pero se han cavado pozos hasta de sesenta metros (Gibson, 1974). El ancho es suficiente para acomodar a uno o más hombres cavando dentro de él. Las paredes del pozo pueden ser reforzadas con rocas o tabiques, que a veces se extienden sobre la superficie del suelo formando el brocal del pozo, el cual evita la contaminación o caídas de personas o animales. En ocasiones el brocal se cubre para asegurar la calidad del agua (Enge y Whiteford, 2000). Los métodos para extraer el agua pueden ser por medio de un cubo y poleas o bien por medio de bombas eléctricas pequeñas (Henao, 2000; González y Terrazas, 2006). 
Figura 2. Componentes de un pozo común

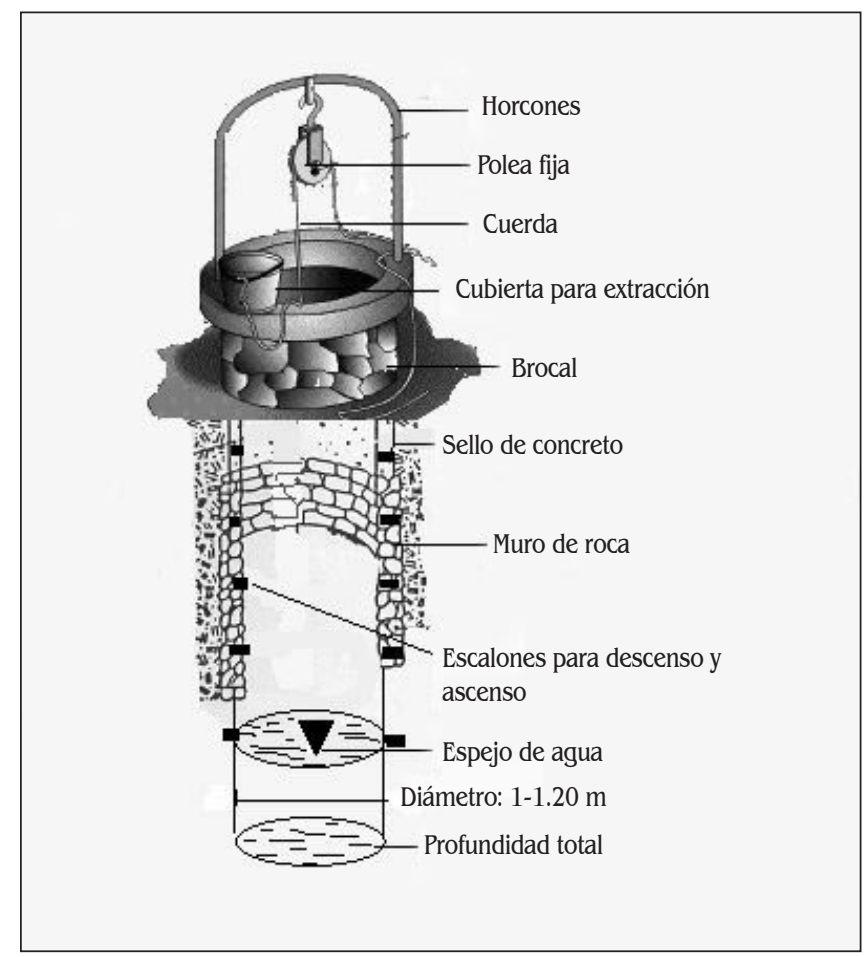

Fuente: tomado de R. Bonfil, 1970.

Los pozos superficiales que explotan aguas subterráneas someras han sido una alternativa de relativamente bajo costo y tecnología simple para el abastecimiento de agua donde no hay o donde son insuficientes las aguas superficiales. A diferencia de los pozos profundos modernos, los pozos superficiales cavados a mano pueden ser costeados por familias de escasos recursos. Los pozos requieren poco mantenimiento que, por lo regular, se circunscribe a la aportación de mano de obra. Para la construcción y operación de un pozo tradicional es posible prescindir por completo de gastos en dinero cuando la familia está en condiciones de realizar todas las tareas necesarias (Del Valle, 1991).

El agua subterránea puede ser extraída por pozos tradicionales bajo un esquema de control individual o familiar, ya que no hay necesidad de recurrir a la colaboración de un grupo social más amplio. Esto otorga a los usuarios una gran independencia para el uso y manejo del recurso, que no cuentan los 
usuarios de aguas superficiales. Por medio de esos pozos existe la apropiación individual de un recurso que es, en esencia, común.

Los pozos han sido y son una alternativa en regiones áridas y semiáridas, pero también en zonas rurales sin acceso a sistemas de agua potable. En las zonas rurales de México, cuando una familia local se establece en una nueva casa, lo primero que asegura es la dotación de agua; en muchas regiones, la forma más sencilla es perforando un pozo.

Una de las desventajas de los pozos tradicionales es que el nivel freático puede estar contaminado por filtración de aguas residuales, por lo que el agua obtenida sólo podrá ser utilizada para jardinería, baldear los pisos, fregar, etcétera, en vez de consumo humano (aseo personal, bebida y para cocinar) (Gibson, 1974). Fueron, precisamente, los problemas de salud pública derivados de la contaminación del agua los que motivaron los esfuerzos por expandir los sistemas de agua potable en México. Durante la segunda mitad del siglo XX se aceleró el proceso de construcción de sistemas de agua potable para las comunidades rurales. Así, la cobertura (disponibilidad de agua entubada dentro de la vivienda) en las áreas rurales pasó de 51.2\% en 1990 a 68.0\% en 2000 (Alatorre, 2011). Para 2010, el censo de población reportó que 78.6\% de la población rural mexicana contaba ya con cobertura de agua potable (INEGI, 2011).

A pesar de los grandes avances en la cobertura del servicio a zonas rurales, la calidad del servicio de agua potable en las áreas rurales difiere ampliamente del que se recibe en las áreas urbanas. En las zonas rurales, las redes formales de agua potable funcionan, en el mejor de los casos, algunas horas al día, dos o tres días por semana. Lo más común es la irregularidad en el suministro y son frecuentes los casos de suspensión indefinida del servicio por descomposturas del sistema o bien por falta de pago de la tarifa de electricidad de bombas de pozos profundos (Soares y Vargas, 2008).

A fin de contribuir a conocer en qué medida los pozos tradicionales contribuyen a atender los requerimientos de agua potable en las zonas rurales, se eligió para su estudio la subcuenca del río San Javier (en el curso medio de la Cuenca Alta del río Lerma) ubicada en el occidente del Estado de México, entre los límites de los municipios de Almoloya de Juárez y Villa Victoria (figura 3). Se seleccionó esta área porque Villa Victoria es el municipio que ocupa el segundo lugar con el más alto índice de marginación en el Estado de México (Conapo, 2006) y porque cuenta con acuíferos superficiales que permiten su aprovechamiento por medio de pozos poco profundos, perforados con tecnología tradicional y con los recursos de los mismos pobladores. Asimismo, la cuenca del río Lerma y sus acuíferos forman una de las cuencas más importantes en el país, pues dotan de agua a cerca de 30\% de la población nacional (Conagua, 2005).

Las técnicas utilizadas fueron investigación bibliográfica y documental, así como trabajo de campo. Las fuentes secundarias consultadas fueron libros, artículos especializados, censos de población y documentos varios de la Comisión Nacional del Agua (Conagua). 
Figura 3. Ubicación de la subcuenca del río San Javier en el Estado de México

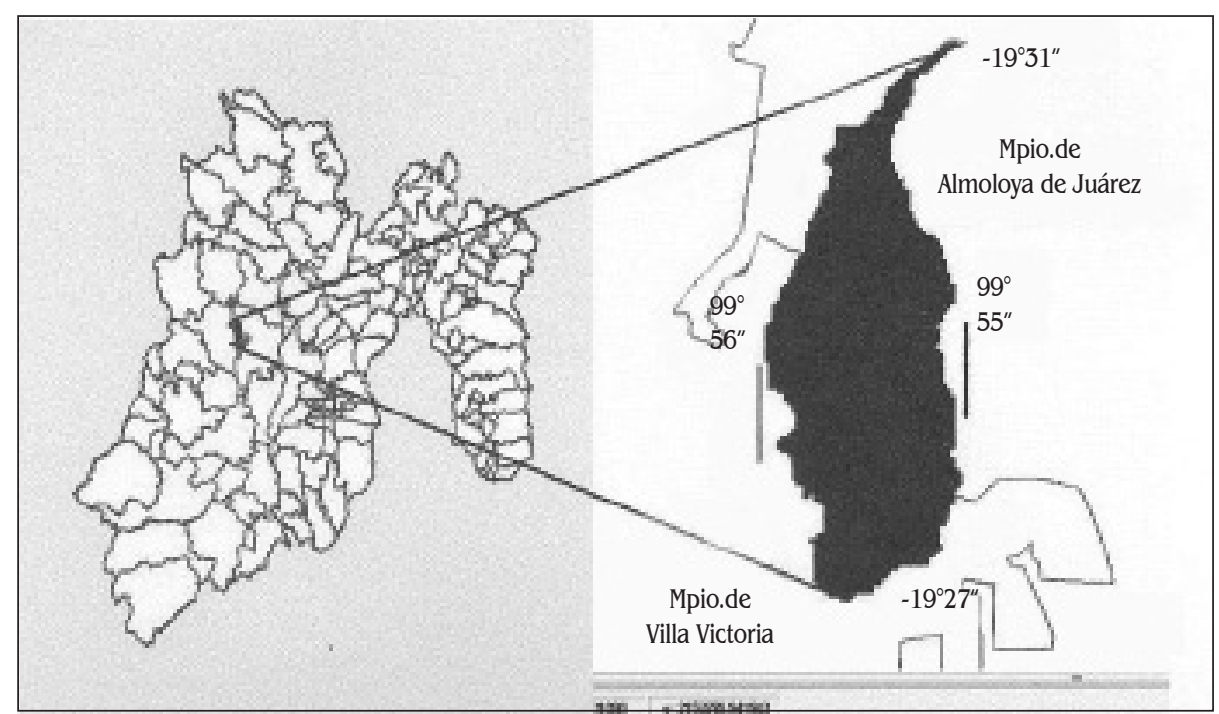

Fuente: elaborado con base en INEGI, 2010.

El trabajo de campo consistió en recorridos por la zona para el registro de infraestructura hidráulica. Se realizaron entrevistas, principalmente con los jefes y jefas de familia de las comunidades para conocer el número de pozos, las viviendas con pozo propio o compartido, modalidades de perforación, estructura, mecanismos de extracción de agua, calidad del agua y tareas de mantenimiento. Se debe señalar que la calidad del agua no se valoró con criterios técnicos, sino, únicamente, por las opiniones y experiencia de los usuarios, su apariencia y la posibilidad de usarse para beber sin aparentes consecuencias negativas para la salud. También se entrevistaron a las autoridades locales, tanto ejidales como municipales, a fin de conocer la estructura y funcionamiento de las redes de agua potable y su capacidad para abastecer los requerimientos de la población. Igualmente, se realizaron entrevistas a autoridades de instituciones participantes como Conagua y la Comisión del Agua del Estado de México (CAEM). El trabajo de campo se realizó durante 2010 y principios de 2011.

El artículo se estructura en cuatro secciones. En la primera sección se presentan las características generales de la subcuenca del río San Javier y los pozos de la zona. En la segunda, se expone la situación en cada una de las localidades respecto al funcionamiento de las redes de agua potable y el papel de los pozos domésticos para garantizar el acceso a esta. La tercera sección incluye la historia laboral de un perforador profesional de pozos (Rodrigo Vázquez Martínez). Al final se presentan las conclusiones derivadas de la investigación. 


\section{La subcuenca del río San Javier y sus pozos}

La subcuenca del río San Javier se origina por los arroyos San Javier, El Nigüe y San Juan. Los tres confluyen en el primero para formar el río San Javier, el cual desemboca en la presa Ignacio Ramírez (figura 4). El almacenamiento se deriva posteriormente al río Lerma.

Figura 4. Localidades, presas y corrientes fluviales de la subcuenca del río San Javier

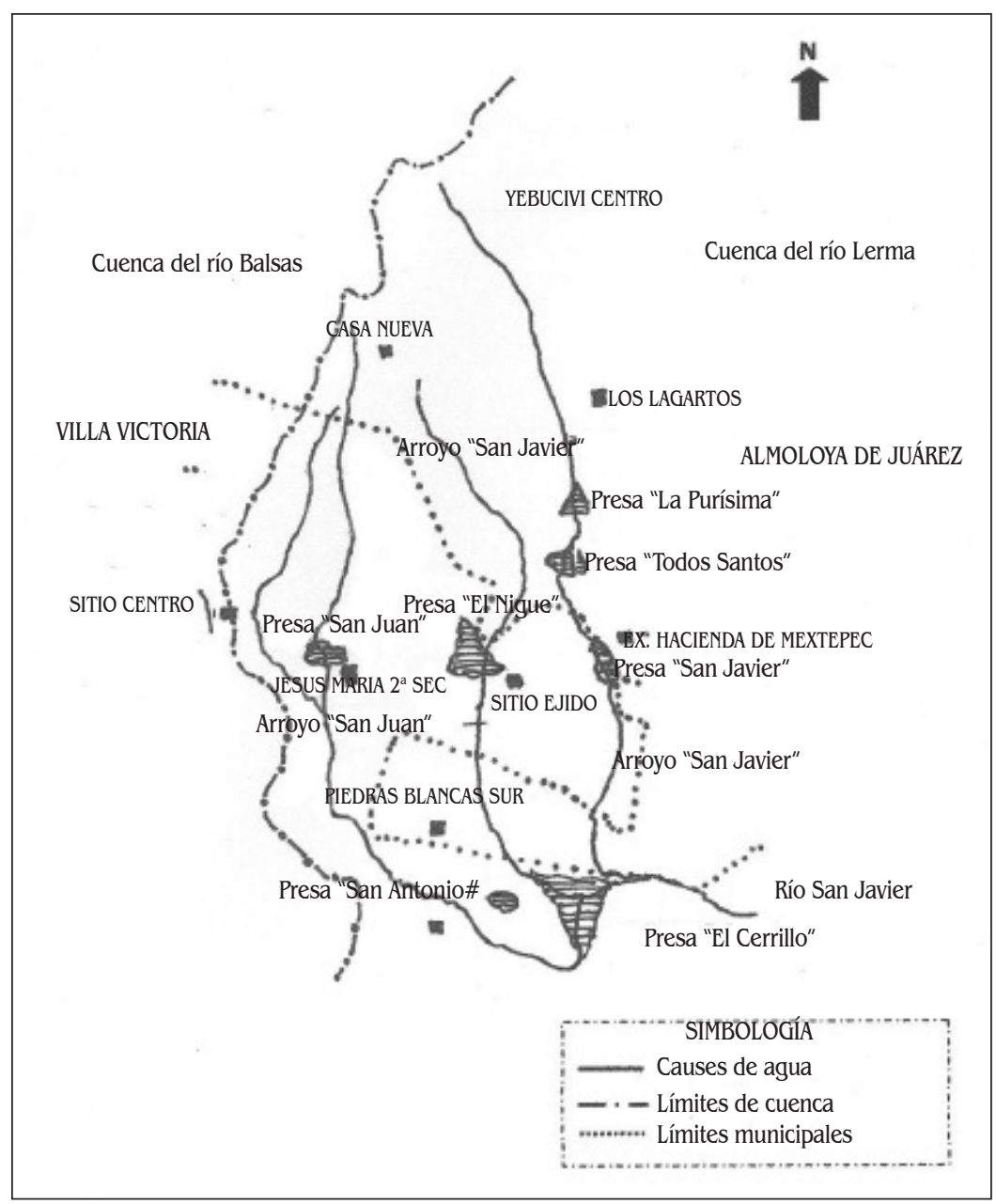

Fuente: foto Manuel Chávez, 2011.

La subcuenca del río San Javier tiene una superficie total 3,348 hectáreas. El área desciende en altitud de norte a sur desde los 3,000 hasta los 2,600 msnm. Forma parte del curso medio de la cuenca alta del río Lerma y está ubicada entre los $19^{\circ} 27^{\prime \prime}$ y $19^{\circ} 31^{\prime \prime}$ lat. norte y $99^{\circ} 55$ y $99^{\circ} 56^{\prime \prime}$ long. oeste. Su régimen pluvial promedio es de $780 \mathrm{~mm}$ al año. Los recursos hídricos benefician con 
riego agrícola y agua para uso doméstico a cinco comunidades: Yebucivi, Mextepec, El Sitio, El Hospital y ejido de Jesús María. En 2010 en estas localidades residían tres mil quinientas familias y una población total de 17,799 personas (INEGI, 2011).

El Plan de Desarrollo Municipal de Villa Victoria, a la cual pertenece una parte de la subcuenca del río San Javier, reporta que en el municipio, cinco mil ciento diez familias se dotaban de agua a partir de 915 pozos o norias (Ayuntamiento de Villa Victoria, 2009).

Durante los recorridos en la subcuenca se encontraron un total de 451 pozos y quince pequeños manantiales en forma de pozos, donde las familias extraen agua para diferentes usos, pero, sobre todo, para consumo doméstico: lavar ropa, uso sanitario, cocinar y agua para beber. Los pozos tienen diversas profundidades, los hay desde seis hasta veintisiete metros. Los perforan en diferentes lugares: dentro de las casas, a unos cuantos metros de las casas y hasta a trescientos metros de los centros urbanos, aunque estos últimos funcionan como pozos comunitarios. Generalmente, la propiedad del pozo es familiar pero se comparten con dos o tres familias vecinas que carecen de agua.

\section{El pozo: orígenes y posesión}

En el pasado, las familias de esta región recurrían únicamente a los manantiales y arroyos para abastecerse de agua potable. La perforación de pozos propiamente dichos en la zona comenzó en la época novohispana y algunos son considerados muy antiguos. Los lugareños no saben quiénes los perforaron, sólo se limitan a decir que los perforaron "los antiguos", porque "desde que ellos tienen uso de razón esos pozos ya existían". Otros comentan que los perforaron hacendados y rancheros, como es el caso de las haciendas de Mextepec, El Sitio y La Gavia. Cabe señalar que durante un recorrido por la zona se observó que varios de ellos no son pozos sino pequeños manantiales de donde brota el agua de manera natural.

No existen fuentes disponibles de información para conocer en qué época comenzaron a perforar pozos comunitarios o en los terrenos de las viviendas. Sin embargo, no cabe duda que la perforación de pozos en ubicaciones cada vez más cercanas a la residencia familiar, permitió una mayor seguridad en el suministro de agua y, sobre todo, evitar largas travesías para el acarreo desde las fuentes de agua permanentes.

En la actualidad, el pozo es una posesión fundamental para las familias de la región. Mientras no haya una dotación de agua segura por las redes formales, las familias dependen de los pozos. Hay expresiones orgullosas como: "Mi pozo produce la mejor agua y más limpia", o bien "iQué voy a hacer sin mi pozo!".

Aunque la Constitución mexicana establece que los propietarios de terrenos tienen libertad de alumbrar las aguas subterráneas (artículo 27, párrafo 5), también señala que en acuíferos sobreexplotados se deberá contar con un permiso 
especial del gobierno federal. Debido a que la zona de estudio se encuentra en un área de veda estricta, se requiere de un permiso de la Conagua para perforar pozos. ${ }^{1}$ Sin embargo, la gente perfora sin solicitar ningún permiso.

En entrevista, el Ing. Carlos Ruiz Becerra, director de Infraestructura Hidráulica de la Conagua en el Estado de México, indicó:

Se necesita pedir permiso, forzosamente, para perforar un pozo o noria, pero la gente no lo hace; en esa zona toda la gente tiene su pocito. Hay una veda total, un permiso seguramente se les negaría y si se sorprendiera a alguien perforando un pozo se le sancionaría, pero no nos damos abasto, por esa zona también hay muchos pozos artesianos los cuales están considerados como manantiales y los manantiales son aguas superficiales nacionales, los cuales para su uso y explotación deben contar con una concesión (Entrevista 23 de septiembre del 2010).

La perforación de pozos continúa porque las autoridades del agua no poseen capacidad operativa para sancionar a todos los infractores. Desde el punto de vista de los habitantes es un derecho incuestionable perforar pozos en los terrenos propios. También los pozos se heredan de padres a hijos como parte del patrimonio familiar y la posesión depende de quien lo construyó y en qué lugar o propiedad se perforó.

\section{Percepción de la calidad del agua de los pozos}

La calidad del agua que aquí se indica no se funda en la NORMA Oficial Mexicana NOM-179-SSA1-1998-Vigilancia y evaluación del control de calidad del agua para uso y consumo humano, distribuida por sistemas de abastecimiento público (Secretaría de Salud, 2000), sino únicamente en las opiniones y experiencias de los habitantes. Desde este punto de vista, la mayor parte no está contaminada, salvo la de aquellos por los que pasa muy cerca el drenaje de las poblaciones. Por ejemplo, María Luisa Laureano Domínguez de la comunidad de Mextepec, indica que debió perforar un pozo nuevo porque pasaron un drenaje a unos dos metros de su pozo antiguo y se contaminó.

De los pozos encuestados, $90 \%$ cuenta con brocal y entre un 15 y un $20 \%$ de los pozos se encuentra tapado por encima del brocal, lo cual disminuye en gran medida su contaminación por aguas superficiales y el peligro de que alguna persona o animal caiga. El que la mayoría no cubra los pozos puede adjudicarse a negligencia, pero también a ciertas creencias. Algunos piensan que al taparlos se llenarán de gusanos, tal es el caso de la Sra. Brígida Vázquez de la O. Otros aseguran que los pozos deben estar destapados: la Sra. Ma. Del Carmen Castelar Sánchez aseguró que el agua llama el agua, que el agua es vida y que por eso hay cada vez menos agua, porque se tapan los pozos.

El agua de los pozos se destina para todo uso, principalmente para el doméstico; para abrevar al ganado y cultivar hortalizas en pequeñas superficies. Hay familias hierven el agua para beber; la mayoría la consumen directamente porque no perciben una relación entre el agua de pozo y problemas de salud.

\footnotetext{
${ }^{1}$ La veda estricta en la cuenca alta del río Lerma se decretó el 10 de agosto de 1965.
} 


\section{Los pozos por localidad}

\section{Yebuciví}

Yebuciví se encuentra en la parte norte de la subcuenca. Cuenta con un sistema de agua potable que comenzó a construirse en 1985 y se concluyó en 1997 (Plan Municipal de Desarrollo de Almoloya de Juárez, 2005). El sistema formalmente benefició a seiscientas familias, pero sólo atendía a cuatrocientas familias. Dicho sistema dejó de funcionar completamente a mediados del 2010 porque se suspendió el suministro de energía eléctrica para bombeo a causa de la falta de pago por parte del Comité de Agua Potable. Ante la situación de emergencia, los habitantes recurrieron a los manantiales de la zona e, incluso, a la compra de agua en pipas, cuyo costo a mediados de 2010 alcanzó cuatrocientos pesos. Por el oneroso gasto por comprar agua, a partir de 2010 muchas familias comenzaron a perforar pozos, práctica que no se realizaba con anterioridad. El agua se encuentra a poca profundidad, aproximadamente a diez metros, pero en época de sequía, que abarca los meses de noviembre a mayo, los pozos se abaten (Entrevista con el Sr. Juan Vargas Martínez, delegado municipal, 15 de noviembre de 2010).

Yebuciví se encuentra a 2,962 metros sobre el nivel del mar (INEGI, 2011), por lo que el agua freática a estas alturas es más difícil de localizar (Plan Municipal de Desarrollo de Almoloya de Juárez, 2005). Anteriormente, no se perforaban pozos en Yebuciví por el temor de no encontrar agua, pero también por lo friable del suelo y porque, al descender la perforación, hubiera derrumbes. A pesar de estos problemas, al menos $80 \%$ de las familias indicaron que han decidido perforar pozos por la grave crisis en el sistema de agua local. En la actualidad, hay veintisiete pozos perforados en pleno funcionamiento; en $60 \%$ de ellos extraen el agua con bomba y en $40 \%$ a mano, con una polea a la que los habitantes denominan garrucha. El $60 \%$ de los pozos se encuentra cubierto en la parte superior del brocal.

Un caso de interés es el del Sr. José Alcántara Vilchis, quien perforó un pozo en la misma sala de su casa. Le instaló una bomba y cuenta con suficiente agua para todas sus necesidades, sin tener que depender de la red de agua municipal con todos los problemas y gastos que ello implica.

Esta comunidad cuenta con un ejido denominado Piedras blancas, ubicado entre las localidades ejido El Sitio y El Hospital, el cual dispone de un sistema de agua potable en pleno funcionamiento. No obstante, existen veinticuatro pozos domésticos con agua a una profundidad aproximada de doce metros, los cuales se usan cuando falla el suministro de agua por la red.

Mextepec

Tiempo atrás, la comunidad de Mextepec del municipio de Almoloya de Juárez, contaba con una mayor cantidad de pozos en operación, pero al construirse los 
sistemas municipales de agua potable, dejaron de usarse. La localidad dispone de un sistema de agua potable manejado por un comité local y dos sistemas nuevos que entrarían en funcionamiento en 2011. La red de agua municipal en uso no proporciona agua en la cantidad necesaria para cubrir las necesidades de la población. Ello ocurre por la antigüedad del sistema y por la falta de mantenimiento. Sobre los nuevos sistemas, la gente opina que no tendrán suficiente presión y que otras fallas técnicas y de manejo impedirán que resuelvan su problema de agua.

Los problemas para el suministro por medio de redes de agua potable han ocasionado que los pozos familiares existentes nuevamente se estén utilizando. También se construyeron nuevos pozos. En Mextepec, solamente se identificaron veintidós pozos en operación. El $80 \%$ de las familias con pozo comparte el agua con familiares más cercanos. Aproximadamente $70 \%$ de las familias extrae el agua mediante polea y $30 \%$ usa bomba. En esta comunidad la profundidad a la que se encuentra el agua oscila alrededor de diecisiete metros. Junto con los pozos se utilizan algunos pequeños manantiales.

Algunas familias de la localidad abandonaron sus pozos argumentando que están contaminados, sobre todo en aquellas áreas que aglutinan mayor población. Para compensar, las personas del lugar están tratando de rehabilitar algunos pozos antiguos y, para asegurar el éxito de los trabajos, llevan ofrendas de flores, canastos de frutas, imágenes de santos, con la idea de agradecer y alcanzar el favor de estos. En esta comunidad, Don Macario Hernández comenta:

Cuando no teníamos el sistema de agua, sacábamos agua de los pozos, casi todos teníamos nuestros pozos y creo que estábamos mejor antes con nuestros pocitos, pero ahora muchos de ellos están contaminados y otros, pues ya se secaron, ya no dan agua. Quizá porque en los pueblos cercanos hicieron cuatro pozos profundos, uno en El Resbaloso, otro en El 92, el de El Hospital y el de Yebuciví. Ya no sabemos qué vamos a hacer, y con eso que las autoridades no se mueven ni hacen nada. Creo que tendremos que volver otra vez a los pozos (Entrevista 20 de octubre de 2010).

En suma, la situación es grave porque el abasto de agua potable por las diversas vías es insuficiente. La población se encuentra frustrada y decepcionada, tanto de ellos mismos como de las autoridades, debido a que la organización local para la administración del sistema de agua potable no ha sido capaz de gestionar oportunamente los trabajos de mantenimiento.

\section{Ejido El Sitio}

Es la comunidad que cuenta con el mayor número de pozos en la subcuenca del río San Javier, son aproximadamente trescientas treinta y cinco, de los cuales diez están abandonados. Cuenta con dos sistemas municipales de agua potable, pero el agua recibida no es apta para uso doméstico porque el tanque de almacenamiento absorbe filtraciones de la presa El Nigüe, la cual recibe residuos de jabón por el lavado de ropa y desechos ganaderos. Así, la población, que 
en 2010 ascendió a dos mil setecientas veinticinco personas, debe continuar usando los pozos. El agua se encuentra a una profundidad de quince metros; afortunadamente, es abundante según percepciones de los habitantes.

En la localidad, 95\% de las familias cuenta con pozo, el resto obtiene agua limpia para consumo doméstico con vecinos. El 80\% de las familias pagó por la perforación y 20\% hizo el pozo por sí mismas. El 90\% de las familias usa polea o garrucha para extraer el agua y 10\% lo hace mediante bombas (Trabajo de campo, diciembre 2010 a febrero de 2011).

El ejido cuenta con un barrio, que es una localidad separada, denominado Sitio Centro, donde la situación es bastante crítica, ya que sólo cuenta con tres pequeños manantiales, de donde se abastece una población de 1,178 personas (INEGI, 2011).

\section{Ejido de Jesús María}

El ejido Jesús María no dispone de un sistema de agua potable por falta de acuerdo entre la población local, sobre el uso del pozo profundo. La localidad cuenta con veinte pozos y la profundidad a la que se encuentra el agua es de, aproximadamente, ocho metros. Debido a que son alrededor de 50 familias, deben compartir el agua de los pozos. No obstante, les alcanza perfectamente, aunque la usan para los más diversos fines. La mayoría de los pozos se encuentran a cielo abierto. El 70\% de las familias usa polea o garrucha para extraer el agua, mientras $30 \%$ lo hace con bomba.

Algunas familias de Jesús María disponen de agua en abundancia de los pozos. Comenta Andrés Ramírez González:

Este pozo lo hice hace unos dieciséis años o más y me ha ido muy bien. Tiene ocho metros de agua y del piso al agua tiene cua metros. Tiene mucha agua y muy buena, no como otros de aquí cerquita que tienen más de diecisiete metros de hondos y apenas tienen unos dos metros de agua. Sólo que a este pozo no he tenido el cuidado de taparlo y por eso, a veces, se caen los guajolotes. Pero lo limpiamos muy de vez en cuando, con mi muchacho; y nos alcanza y da abasto para las dos casas. Cuándo todavía no hacíamos este pozo sacábamos el agua de otro pocito que estaba aquí atrás en la barranca. Ese pozo ya tenía muchos años, pero como era poca gente alcanzaba para todos (Entrevista de octubre de 2010).

\section{Ejido El Hospital}

En el ejido El Hospital la profundidad a la que se encuentra el agua de los pozos es menor que en otras localidades, aproximadamente diez metros. El agua es abundante porque dicen nunca se abaten los niveles; así cuando deben limpiarlos, les cuesta mucho extraer toda el agua. Ahí se localizaron veinticuatro pozos, veinte de ellos en pleno funcionamiento, tres abandonados y uno que fue tapado porque representaba un peligro por estar descubierto y sin brocal. El Hospital es la comunidad donde mejor funciona el sistema de agua municipal. No obstante, veintidós familias siguen usando el agua de los pozos para beber y otras cuatro los mantienen como reserva. Ahí se encontró un pozo con una pro- 
fundidad de veintisiete metros con abundante agua. Aproximadamente, $15 \%$ de ellos se encuentra cubierto para su protección. El cien por ciento de ellos extrae el agua mediante poleas o garruchas.

\section{Resumen}

La situación de los pozos superficiales vis a vis los sistemas de agua potable en cada una de las cinco comunidades estudiadas se muestran en la tabla 1. Solamente en una de las comunidades funcionaba bien el sistema de agua potable. En tres localidades se abastecían de agua doméstica en cantidad suficiente por medio de los pozos tradicionales. Solamente en una comunidad se enfrentaban problemas de abastecimiento de agua porque el suministro de la red era insuficiente y porque algunos pozos locales se habían abatido o estaban contaminados.

Tabla 1. Sistemas de agua potable y los pozos. Resumen por localidades

\begin{tabular}{|c|c|c|c|c|}
\hline Localidad & $\begin{array}{l}\text { Situación del siste- } \\
\text { ma de agua potable }\end{array}$ & $\begin{array}{l}\text { Papel actual de los } \\
\text { pozos }\end{array}$ & $\begin{array}{c}\text { Situación en el } \\
\text { suministro de agua }\end{array}$ & $\begin{array}{l}\text { Características } \\
\text { de los pozos }\end{array}$ \\
\hline Yebucibí & $\begin{array}{l}\text { El sistema de agua } \\
\text { potable dejó de } \\
\text { funcionar en } 2010 \\
\text { por suspensión del } \\
\text { servicio de energía } \\
\text { eléctrica. }\end{array}$ & $\begin{array}{l}\text { No se acostumbraba el } \\
\text { uso de pozos. Ante la } \\
\text { crisis actualmente se } \\
\text { están construyendo. }\end{array}$ & $\begin{array}{l}\text { Los pozos actuales } \\
\text { brindan un suministro } \\
\text { adecuado de agua. }\end{array}$ & $\begin{array}{l}\text { El agua se encuentra } \\
\text { a poca profundidad, } \\
\text { aproximadamente a } \\
\text { diez metros, pero en } \\
\text { épocas de sequía los } \\
\text { pozos se abaten. }\end{array}$ \\
\hline Mextepec & $\begin{array}{l}\text { La red municipal de } \\
\text { agua potable es insu- } \\
\text { ficiente. No hay con- } \\
\text { fianza en que los dos } \\
\text { nuevos sistemas que } \\
\text { entrarán en operación } \\
\text { resuelvan el problema. }\end{array}$ & $\begin{array}{l}\text { Existían pozos antes } \\
\text { del sistema de agua } \\
\text { potable y se dejaron } \\
\text { de utilizar; ahora se } \\
\text { están rehabilitando y } \\
\text { se construyen nuevos } \\
\text { pozos. }\end{array}$ & $\begin{array}{l}\text { Existe un problema } \\
\text { grave de suministro } \\
\text { de agua potable. } \\
\text { Algunos pozos están } \\
\text { contaminados y otros } \\
\text { se han abatido. }\end{array}$ & $\begin{array}{l}\text { La profundidad a la } \\
\text { que se encuentra el } \\
\text { agua oscila en alre- } \\
\text { dedor de diecisiete } \\
\text { metros. }\end{array}$ \\
\hline $\begin{array}{l}\text { Ejido El } \\
\text { Sitio }\end{array}$ & $\begin{array}{l}\text { El agua potable se } \\
\text { contamina en el } \\
\text { tanque de almace- } \\
\text { namiento con filtra- } \\
\text { ciones de la presa El } \\
\text { Nigüe. }\end{array}$ & $\begin{array}{l}\text { Los pozos antiguos } \\
\text { se han rehabilitado y } \\
\text { se están perforando } \\
\text { otros. }\end{array}$ & $\begin{array}{l}\text { Los pozos, que son } \\
\text { numerosos, permiten } \\
\text { un adecuado suminis- } \\
\text { tro de agua potable. }\end{array}$ & $\begin{array}{l}\text { La tabla de agua } \\
\text { se encuentra entre } \\
\text { quince y diecisiete } \\
\text { metros. La cantidad } \\
\text { de agua es abundante. }\end{array}$ \\
\hline Jesús María & $\begin{array}{l}\text { Existe un sistema de } \\
\text { agua potable pero } \\
\text { no se encuentra en } \\
\text { operación. }\end{array}$ & $\begin{array}{l}\text { Los pozos existentes } \\
\text { son suficientes para } \\
\text { abastecer a la po- } \\
\text { blación. }\end{array}$ & $\begin{array}{l}\text { Los pozos proporcio- } \\
\text { nan agua abundante. }\end{array}$ & $\begin{array}{l}\text { La tabla de agua se } \\
\text { encuentra aproxima- } \\
\text { damente a diez me- } \\
\text { tros. Algunas familias } \\
\text { disponen de agua } \\
\text { abundante. }\end{array}$ \\
\hline El Hospital & $\begin{array}{l}\text { Funciona bien el } \\
\text { sistema de agua } \\
\text { potable. }\end{array}$ & $\begin{array}{l}\text { Se sigue usando el } \\
\text { agua de los pozos } \\
\text { para beber y como } \\
\text { reserva. }\end{array}$ & $\begin{array}{l}\text { El suministro de agua } \\
\text { es adecuado, tanto de } \\
\text { la red de agua potable } \\
\text { como de los pozos. }\end{array}$ & $\begin{array}{l}\text { La tabla de agua } \\
\text { se encuentra a diez } \\
\text { metros. El agua que } \\
\text { producen es abun- } \\
\text { dante. }\end{array}$ \\
\hline
\end{tabular}

Fuente: Manuel Chávez. Trabajo de campo realizado durante 2010 y principios de 2011. 


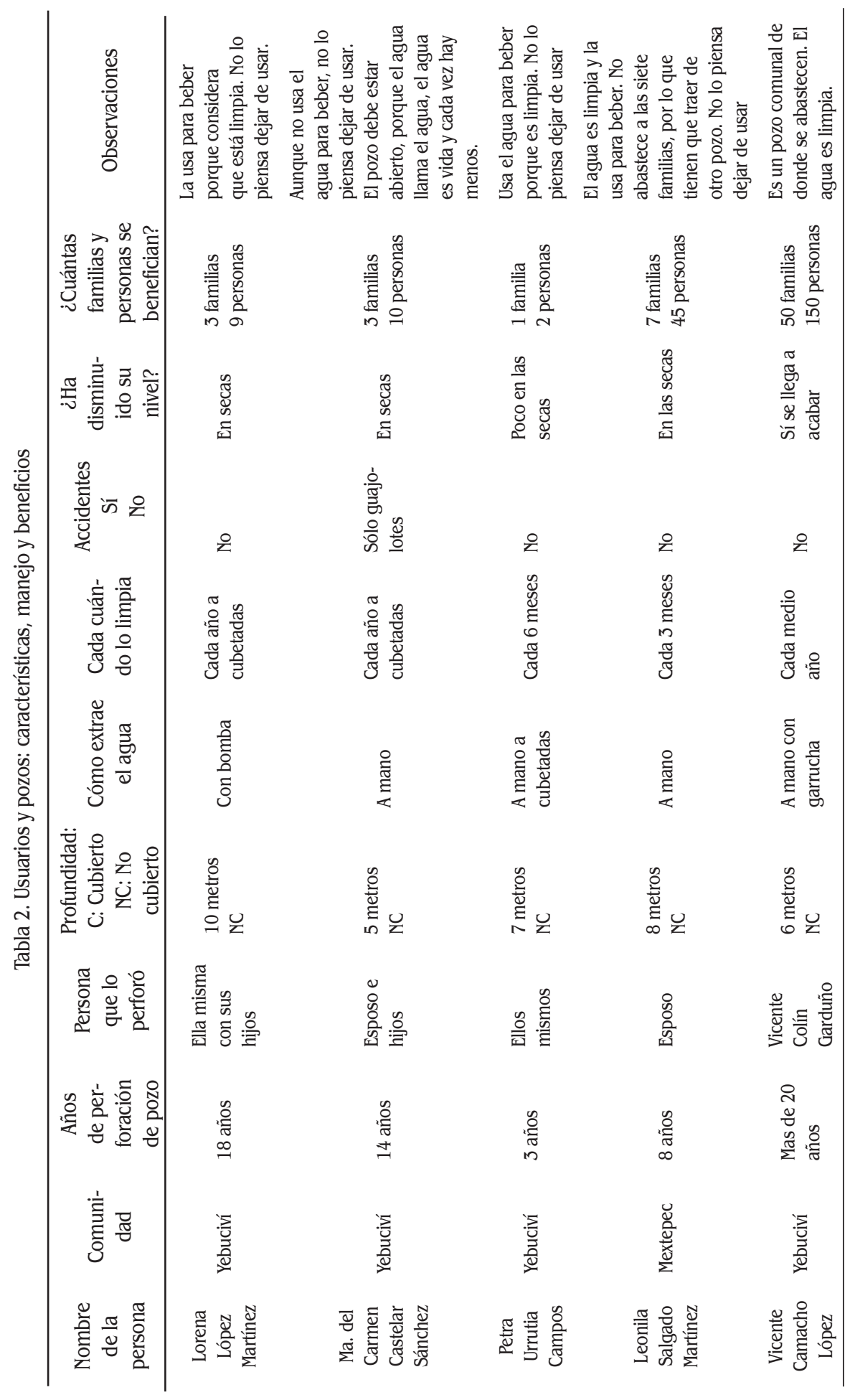




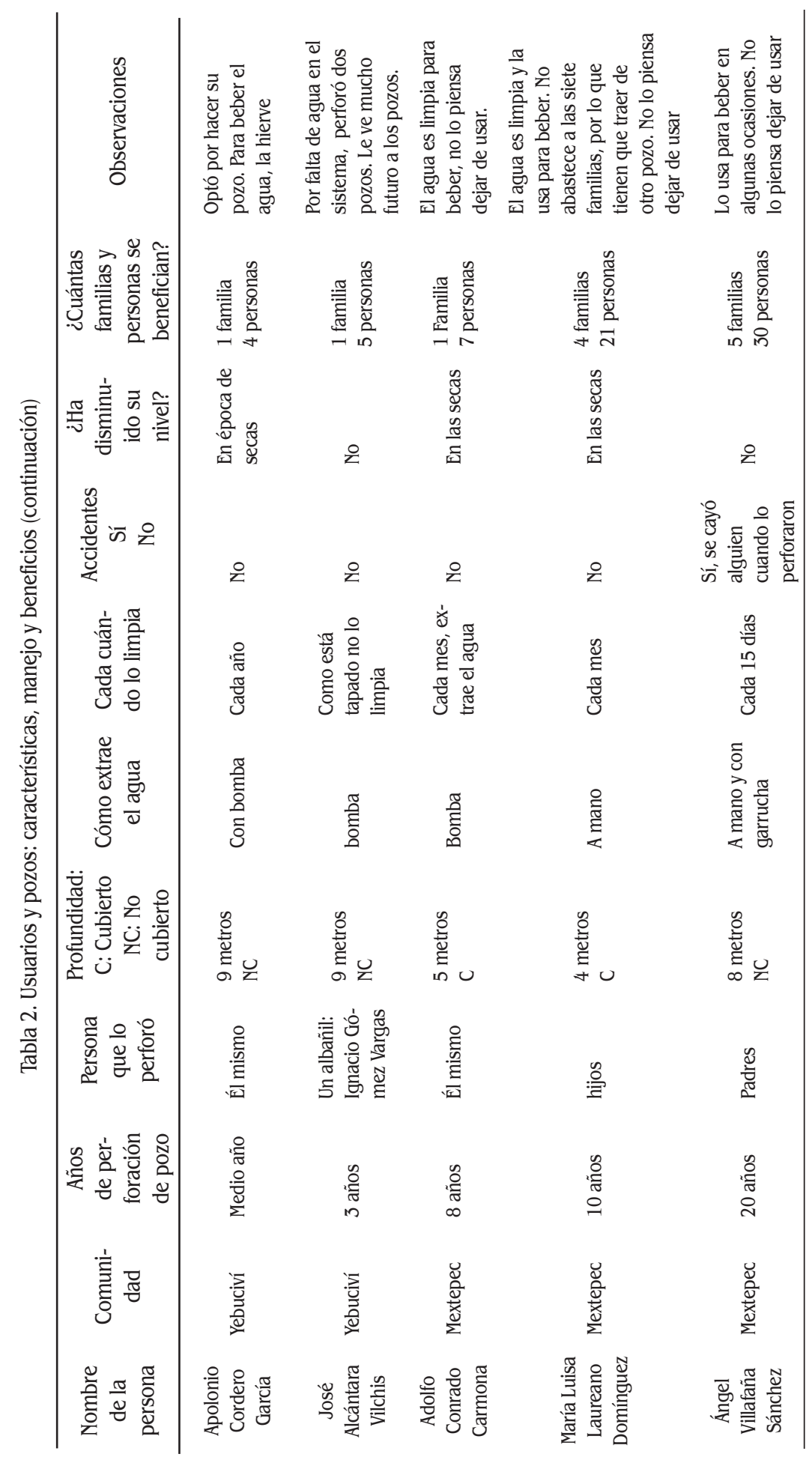




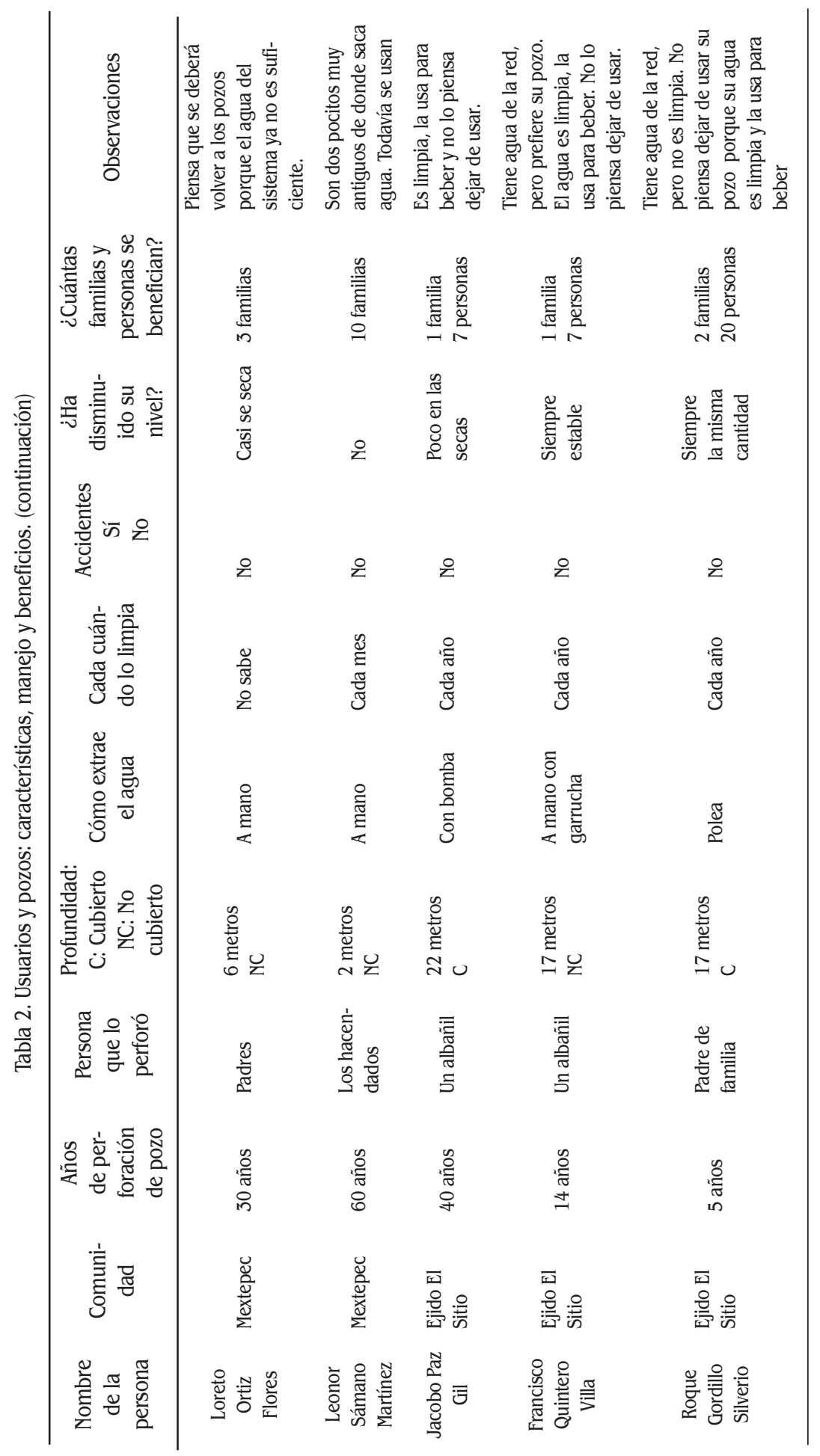




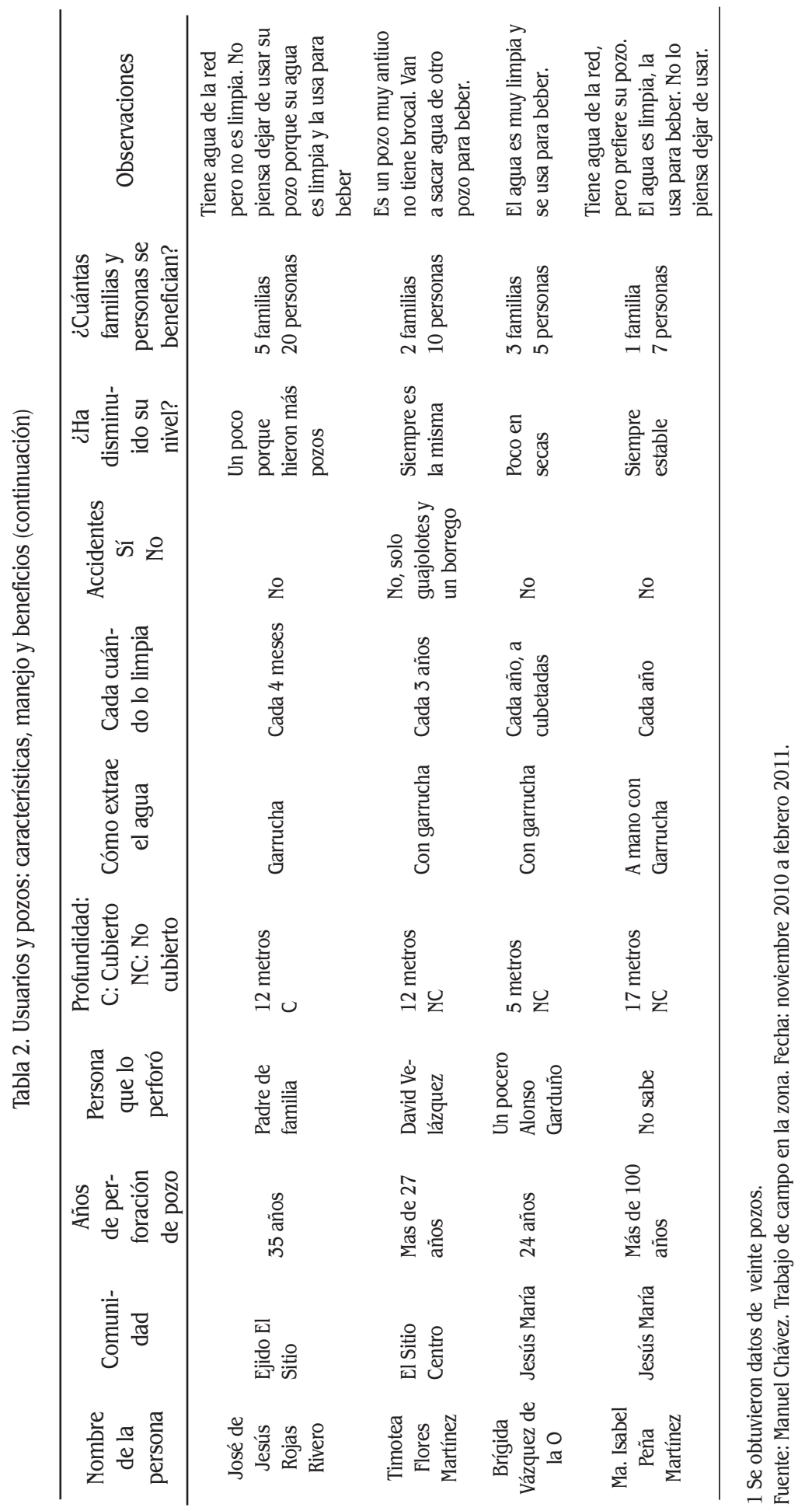


Según los resultados de las entrevistas a usuarios de pozos, expuestos en la tabla 2, la profundidad promedio a la que se encuentra la tabla de agua es de 8.25 metros de profundidad, aunque puede alcanzar veintisiete metros.

El año de la construcción de los pozos varía mucho. Algunos tienen medio año, pero hay de sesenta y hasta más de cien años. Cabe señalar que algunos denominados pozos son en realidad pequeños manantiales cuya agua fluye de manera constante y en pequeñas cantidades. La personas encargadas de su perforación fueron en su mayoría familiares de los mismos usuarios, aunque en seis casos contrataron a personas ajenas a su familia, lo cual representa $30 \%$. El $40 \%$ de las familias usa bomba para la extracción. En $70 \%$ de las familias entrevistadas no se encuentra cubierto el pozo. No obstante, no han tenido accidentes graves. En promedio en la subcuenca un pozo abastece a 5.8 familias. El tiempo promedio en que los usuarios tardan en limpiar su pozo es de siete meses. El 55\% de los entrevistados (once personas) mencionaron que su pozo se abate un poco en épocas de sequía. No obstante, los pozos brindan seguridad y confianza, sobre todo cuando los sistemas de agua potable municipales por diversas causas son disfuncionales, sea por el mal funcionamiento de los comités, falta de acuerdos entre autoridades, problemas técnicos con los equipos o la dotación de corriente eléctrica. Así, en su totalidad la gente menciona que no dejará de usar los pozos.

\section{Experiencias de un pocero}

Los siguientes párrafos corresponden a la entrevista realizada al Sr. Rodrigo Vázquez Martínez, quien es pocero profesional; reside en el ejido El Sitio. La entrevista se realizó el día 11 de marzo del 2011 en el ejido El Sitio, municipio de Villa Victoria. La entrevista brinda datos sobre el oficio: la tecnología usada, las bases para la toma de decisiones sobre dónde perforar, sus percepciones sobre las señales y las fuentes de la contaminación de pozos, sus conocimientos de la estructura del suelo y, en general, las experiencias vividas como perforador de pozos tradicionales.

Llevo más de veinte años perforando pozos. Empecé cuando don Moisés me pidió que le perforara su pozo y pues me animé. Nadie me enseñó, sólo empecé por necesidad. Ahora me dicen que parezco cerdo, que ando abriendo hoyos por dondequiera, pero para esto hay que tener valor, porque no cualquiera se avienta. He perforado muchos, yo creo que más de veinte, aquí en esta comunidad de El Sitio, Tabernillas, San Marcos, El Resbaloso, Sitio Centro, El Hospital, y hasta por el rumbo de Toluca me han pedido que vaya a perforar, y ya no me acuerdo donde más.

La información proporcionada por el Sr. Vázquez acerca de su ingreso a la actividad sugiere que el oficio de pocero no requiere un proceso de adiestramiento práctico y que cualquier hombre saludable puede iniciarse en él. Aunque puede haber dudas al respecto, esto se confirma porque la mayoría de las familias indicaron que emprendieron la perforación con sus propios recursos y sin contratar a un pocero profesional. 
El Sr. Vázquez considera que en todas partes hay agua y no es necesaria una varita mágica. Sin embargo, para evitar contaminación, al perforar un pozo procura que no haya estercoleros cerca y que las fosas sépticas estén a no menos de cincuenta metros de distancia.

Para empezar a perforar se ubica el lugar, se marca el área de un metro a un metro veinte de diámetro. Posteriormente, se ponen las bases para el brocal, de modo que esté bien sujeto con el tepetate y no se derrumbe. Se instalan los horcones para fijar las cuerdas con la garrucha. Las herramientas usadas para excavar son únicamente un talacho y una pala rabones. Cuando menos dos personas deben ejecutar el trabajo de perforación y después de diez metros es preferible que sean tres. Solamente una persona puede estar adentro excavando, bien sujeta con cuerdas, mientras que otra persona arriba se encarga de subir la cubeta con la tierra. Esas dos personas se turnan en el trabajo cada hora. El principal peligro es un derrumbe de las paredes del pozo, pero también una sola piedra que se caiga puede herir gravemente al perforador.

La profundidad a la que se localiza el espejo de agua es variable, pero en la región se puede encontrar hasta a seis metros. La mayor profundidad a la que el Sr. Vázquez ha hallado agua es a veinte metros. En las partes altas, dice, el agua se encuentra hasta los treinta metros, pero ahí no conviene perforar porque el terreno es muy frágil y son frecuentes los derrumbes.

Es posible terminar de excavar un pozo en una semana aproximadamente a razón de dos metros diarios. Cuando se encuentra agua se dificulta el trabajo, pero debe continuarse excavando extrayendo el líquido que se acumula con una bomba. La profundidad final del agua en el pozo es de 1.20 metros, pero puede alcanzar hasta dos y tres metros: Vemos las paredes del pozo y si vemos que lagrimea de las paredes, quiere decir que todavía le falta. Para mí un pozo bueno es aquel que no lagrimea y que la mayor cantidad de agua sale de abajo como borbollones, venas a los lados y muchos veneritos.

Los honorarios por perforar un pozo en 2010 se cobraban a razón de cuatrocientos pesos por metro. Después de los diez metros de profundidad, el pago se eleva a seiscientos pesos por metro. En promedio el costo por mano de obra en la perforación de un pozo en ese año ascendía a ocho mil doscientos pesos. La construcción de un brocal y otros accesorios se cobra por separado.

Cuando se termina el pozo, es tradicional realizar una celebración por cuenta de la familia. Lo usual es preparar un mole de guajalote y comprar una botella de tequila para cada uno de los poceros.

\section{Conclusiones}

Los datos oficiales sobre cobertura de agua potable en las zonas rurales no proporcionan una visión realista de lo que ocurre en esas áreas. En los casos aquí reseñados ha quedado de relieve que los sistemas municipales de agua potable rurales no proporcionaban, en la mayoría de los casos, abastecimiento continuo y suficiente del líquido. En la zona estudiada, esto ocurre por múltiples causas: 
por la obsolescencia de los sistemas construidos, por deficiencias técnicas en el diseño y construcción de las redes, por la contaminación durante la conducción del agua, por la deficiente administración de los Comités de Agua Potable que deriva en falta de mantenimiento de los sistemas e imposibilidad de recaudar las cuotas para el pago del servicio de energía eléctrica que abastece los pozos profundos y rebombeos.

Por los problemas en los sistemas de agua potable, en cuatro de cinco localidades estudiadas, los pozos domésticos superficiales contribuyen sustancialmente a mejorar el grado de seguridad en el suministro de agua a las familias, e incluso llegan a ser la única fuente de agua.

Los pozos superficiales se han usado en la zona desde hace siglos, por lo cual existe un conocimiento y tecnología local para la construcción de estos. Otra ventaja de los pozos tradicionales es que, por su poca profundidad, la construcción en muchos casos no implica gastos monetarios mayores. Así, la mayor parte de las perforaciones fueron ejecutadas por miembros de la misma familia. Además, los pozos de este tipo operan con un mínimo de insumos externos en todas las fases, lo cual brinda un alto grado de autonomía. También los pozos familiares tienen una función social más amplia, porque son compartidos de manera gratuita con vecinos. Algunos son pozos comunitarios, uno de este tipo atendía a cincuenta familias y más de ciento cincuenta personas en Yebuciví. En suma, la organización que se requiere para la construcción, operación y mantenimientos de los pozos tradicionales es simple y está al alcance de la mayor parte de las familias en las comunidades estudiadas.

Así, los pozos tradicionales han sido hasta ahora la solución para la dotación mínima necesaria de agua potable de buena calidad en dichas comunidades: brindan seguridad, independencia y bienestar en medio de la crisis en los sistemas municipales de agua potable. Asimismo, constituyen un patrimonio valioso de las familias.

No obstante, la cantidad y calidad de aguas subterráneas superficiales dependen de factores diversos, algunos no controlables. Entre los aspectos de índole natural que pueden variar en el tiempo en una misma área están los cambios en las precipitaciones pluviales, estacionales o a largo plazo. Pero la disponibilidad también puede modificarse por factores de origen humano o antrópico en el nivel local o regional, como es la extracción total de agua en un área determinada, los cambios en la permeabilidad del suelo atribuibles a la deforestación y cambios de uso del suelo en las zonas de recarga y por contaminación con aguas negras o agroquímicos.

Si bien, la mayoría de los poseedores de pozos consideraron el agua de buena calidad y apta para consumo doméstico, es también verdad que se registraron algunos casos de pozos contaminados, los cuales fueron atribuidos a la cercanía de fosas sépticas o drenajes. Afortunadamente, la población local tiene conocimiento de las fuentes de contaminación de los pozos y aplica acciones para evitar este problema o los clausura, como en el caso de Mextepec. 
Por otro lado, vecinos de una localidad reportaron el abatimiento total del agua en varios pozos, lo cual se atribuye a la perforación de pozos profundos. Esto se confirmó por lo señalado por Esteller y Díaz (2002), quienes mencionan que la sobreexplotación por pozos profundos del acuífero en la cuenca del alto Lerma abate a dicho acuífero un promedio de $1.4 \mathrm{~m} /$ año.

Por otro lado, es necesario considerar que la disponibilidad de agua para su aprovechamiento por pozos someros apta para consumo humano no se incrementa, mientras que el crecimiento de la población eleva continuamente los requerimientos del vital líquido.

La zona estudiada cuenta con recursos de agua que han permitido a sus habitantes compensar por medio de pozos superficiales las carencias de los sistemas de agua potable. Pero no es posible extender este caso a todas las localidades rurales del país, razón por la cual es necesario conocer las condiciones que enfrenta la gente rural para el suministro de agua para consumo humano directo y establecer acciones emergentes.

Nota: los nombres del perforador de pozos y de los poseedores de pozos son ficticios.

\section{Pozos en la subcuenca del río San Javier}

Figura 5. Antiguos pozos-manantiales más de 150 años de historia en Jesús María

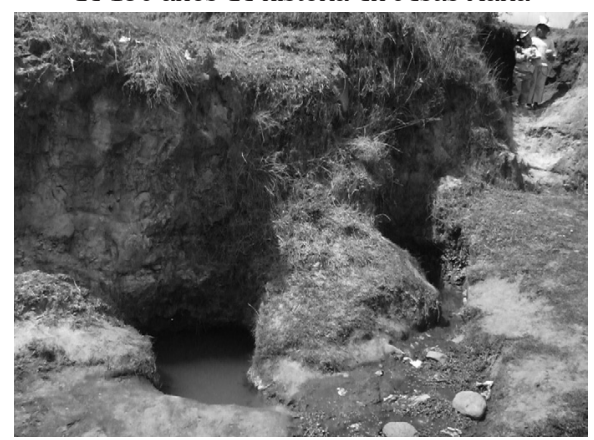

Fuente: foto Manuel Chávez, 2011.

Figura 7. Vista del pozo de la familia Cortés, en cuyo interior se encuentra una bomba para la extracción de agua, en el ejido El Sitio

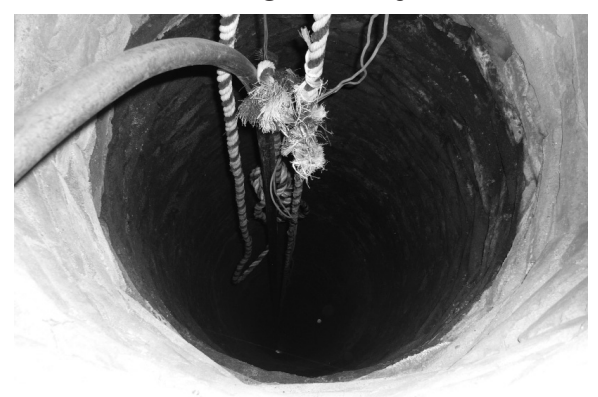

Fuente: foto Manuel Chávez, 2011.
Figura 6. Pozo de la familia Ríos en el ejido El Sitio, con brocal, cubierto y con garrucha

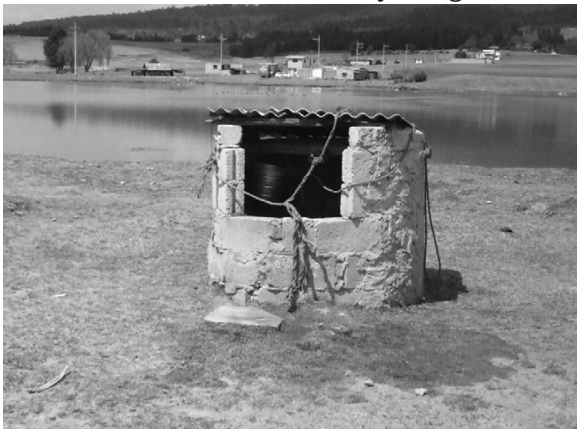

Fuente: foto Manuel Chávez, 2011

Figura 8. Una rueda en forma de polea con manivela para extraer agua de un pozo, en el ejido El Hospital

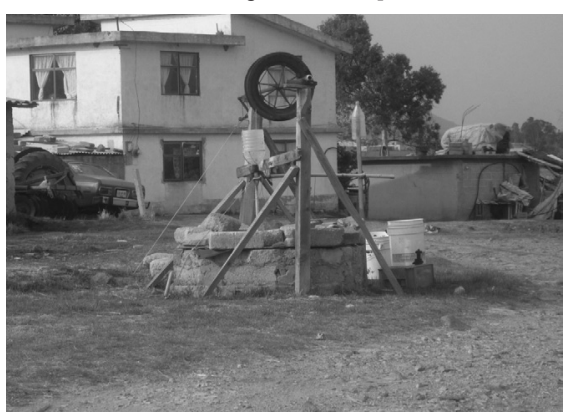

Fuente: foto Manuel Chávez, 2011. 


\section{Bibliografía}

Alatorre, A. (2011) "Falta agua entubada a treinta por ciento de viviendas" Agencia Reforma. 20 de marzo de 2011. En <http://www.elmañana.com.mx> (Accesado el 20 de mayo del 2011).

Bonfil, R. (1970) La vivienda campesina. México, Instituto de Capacitación del Magisterio, Secretaría de Educación Pública.

Conagua (Comisión Nacional del Agua) (2005) Estadísticas agrícolas e hidráulicas de los distritos de riego de México. México, Subdirección General de Infraestructura Hidroagrícola, Gerencia de Distritos y Unidades de Riego.

Conapo (Consejo Nacional de Población) (2006) Índices de marginación 2005. México, D. F.

Chávez, G. R. (1989) "Panorama actual de las aguas subterráneas" Ponencia en Seminario Internacional sobre Tecnificación de Riego y Uso Racional de la Energía. Banco de México y SARH, México.

De Reina, C. y C. De Valera (1990) La Biblia versión 60. México, Sociedad Bíblica Mexicana.

Del Valle, F. (1991) Aguas subterráneas. Chapingo, Universidad Autónoma Chapingo. Dirección de Difusión Cultural.

Enge, K. y S. Whiteford (2000) "Tehuacán, campesinado e irrigación" en J. Palerm y T. Martínez (comp.) Antología sobre pequeño riego "Organizaciones autogestivas. Volumen II, Chapingo, Plaza y Valdés Editores-Colegio de Postgraduados.

Gibson, U. y S. Rexford (1974) Manual de los pozos pequeños: localización, diseño, construcción, uso y conservación. México, LIMUSA Noriega.

González, A. y B. Terrazas (2006) "Pueblos indígenas de Oaxaca". Oaxaca, Oax. En <http://www.aquioaxaca.com/index.php> (Accesado el 21 de mayo del 2011).

Henao, L. (2000) "El valle de Tehuacán" en J. Palerm y T. Martínez (comp.), Antología sobre pequeño riego, Organizaciones autogestivas. Volumen II, Chapingo, Estado de México, Plaza y Valdés Editores-Colegio de Postgraduados.

Esteller, M. y C. Díaz, (2002) Enviromental Effects of Acuifer Overexplotation: A Case Study in the Highlands of México. Toluca, Estado de México, Centro Interamericano de Recursos del Agua, Facultad de Ingeniería, Universidad Autónoma del Estado de México.

Franco, E. (2004) "La arquitectura: testimonio de un tiempo lejano y distante" México, D. F. En <www.architecthum.edu.mx/Architecthumtemp/ensayos/.../efranco. htm > (Accesado 24 de noviembre 2011).

INEGI (Instituto Nacional de Estadística Geografía e Informática) (2010) Sistemas de Información Geográfica (IDRISI). Aguascalientes, México.

(2011) Censo de Población y Vivienda 2010. Aguascalientes, México. Disponible en <http://www.inegi.org.mx/est/> (Accesado el 27 de mayo del 2011).

H. Ayuntamiento Constitucional de Almoloya de Juárez (2005) Plan Municipal de Desarrollo de Almoloya de Juárez. Almoloya de Juárez, Estado de México.

H. Ayuntamiento Constitucional de Villa Victoria (2009) Plan de Desarrollo Municipal 2009-2012. Villa Victoria, Estado de México.

Rojas, T., J. L. Martínez y D. Murillo (2009) Cultura hidráulica y simbolismo mesoamericano del agua en el México prehispánico. Instituto Mexicano de Tecnología del Agua-CIESAS, Jiutepec, Morelos.

Ruiz, C. (2010) Entrevista 23 de septiembre del 2010. Toluca, México. Director de Infraestructura Hidráulica de la Conagua en el Estado de México. 
Secretaría de Salud (2000) Normas oficiales para la calidad del agua en México. En < http://www.facmed.unam.mx/sss/nom/normas\%20> (Accesado 8 de febrero del 2011).

Soares, D. y S. Vargas (2008) "El debate actual del agua: entre la economía, el derecho humano y la sustentabilidad" en D. Soares y S. Vargas (comp.), La gestión de los recursos hídricos: realidades y perspectivas. Tomo 1, Guadalajara, Instituto Mexicano de Tecnología del Agua-Universidad de Guadalajara, Jiutepec, Morelos y Guadalajara, Jalisco.

Vázquez, R. V. (2011) Pocero profesional. Entrevista 11 de marzo del 2011, ejido El Sitio, Estado de México.

Vargas, J. (2010) Entrevista 15 de noviembre de 2010. Delegado municipal de Yebucibí, Yebucibí, municipio de Almoloya de Juárez, Estado de México. 